\title{
Thermal and curl properties of PET/PP blend fibres compatibilized with EAG ternary copolymer
}

\author{
YONG WAN PARK ${ }^{1}$, MIRA PARK ${ }^{2}$, HAK YONG KIM ${ }^{3}$, HWAN CHUL KIM ${ }^{2}$, \\ JONG CHEOL LIM ${ }^{4}$, FAN-LONG JIN ${ }^{5}$ and SOO-JIN PARK ${ }^{6}$, \\ ${ }^{1}$ Korea Institute of Convergence Textile, Iksan 570-330, Republic of Korea \\ ${ }^{2}$ Department of Organic Materials and Fiber Engineering, Chonbuk National University, Jeonju 561-756, \\ Republic of Korea \\ ${ }^{3}$ Department of BIN Convergence Technology, Chonbuk National University, Jeonju 561-756, Republic of Korea \\ ${ }^{4}$ Uno \& Company Co. Ltd., Wanju 565-904, Republic of Korea \\ ${ }^{5}$ Department of Polymer Materials, Jilin Institute of Chemical Technology, Jilin City 132022, People's Republic of China \\ ${ }^{6}$ Department of Chemistry, Inha University, Nam-gu, Incheon 402-751, South Korea \\ *Author for correspondence (sjpark@inha.ac.kr)
}

MS received 12 July 2017; accepted 6 December 2017; published online 26 July 2018

\begin{abstract}
Blends of polyethylene terephthalate (PET)/polypropylene (PP) and the ternary copolymer ethylene-acrylic ester-glycidyl methacrylate (EAG) as the compatibilizer were prepared using a twin-screw extruder. The thermal properties, densities and morphologies of the blends were determined using various techniques. Next, PET/PP blend fibres were prepared using a melt-spinning system, and their curl properties were investigated. Scanning electron microscopy (SEM) results showed that the number of PP particles in the PET matrix and size of the PP phase decreased as the EAG content increased. The melting temperature $\left(T_{\mathrm{m}}\right)$ and cooling crystallization $\left(T_{\mathrm{cc}}\right)$ values of PP in the PET/PP blends decreased significantly after the addition of $1 \%$ EAG. The density of the PET/PP blend fibres decreased significantly with increase in the EAG and PP contents. After curl formation, the curl length of PP in the fibres was shorter than that of PET.
\end{abstract}

Keywords. PET; PP; compatibilizer; thermal properties; curl.

\section{Introduction}

Polymer blending is a widely used method for producing novel high-performance organic materials without synthesizing completely new polymers. The materials produced using this method synergistically exhibit the properties of two or more polymers that were used as starting materials $[1,2]$.

Several studies were reported for the preparation and characterization of polyethylene terephthalate (PET)/ polypropylene (PP) blends. PET/PP blends can be readily processed by extrusion and injection moulding processes. The processed blends have good mechanical properties, low melt viscosities, good spinnability and relatively low costs. Thus, these blends were used as synthetic fibres for applications, e.g., in electronics, in food packaging and beverage containers and in film and automotive technologies. Of the various blends that were studied, PET/PP blends and their fibres were used extensively, and high-quality wigs are the most important application [3-6].

However, PET and PP are immiscible owing to their different chemical natures and polarities. As a result, blends of these polymers exhibit phase separation, forming a continuous PET phase (matrix) and a discontinuous PP phase (dispersed phase) $[7,8]$. Thus, a suitable compatibilizer is usually used to improve the compatibility between PET and PP. The blending of PET and PP aided by various compatibilizers was explored by several researchers. The most commonly used compatibilizers can be divided into PP-based polymers and copolymers. PP-based polymers include maleic anhydride-modified PP and glycidyl methacrylate-grafted PP [9-12], and common copolymers are a hydrogenated styrene-butadiene-styrene block copolymer, a glycidyl-methacrylate-modified styreneb-(ethylene-co-olefin) block copolymer, a n-butyl acrylate glycidyl methacrylate ethylene terpolymer, an ethyleneglycidyl methacrylate copolymer, and poly(ethylene-comethyl acrylate-co-glycidyl methacrylate) [13-18]. A suitable compatibilizer not only improves the compatibility between PET and PP, but also improves the characteristics of the resulting blends. Additionally, the fibres of the resulting PET/PP blend can be used as wig fibres to mimic human hair.

In this study, PET/PP blends and their fibres were prepared using an ethylene-acrylic ester-glycidyl methacrylate ternary copolymer (EAG) as the compatibilizer. The thermal properties, densities and morphologies of the synthesized fibres were investigated using differential scanning calorimetry (DSC), dynamic mechanical analysis (DMA), densitometry and scanning electron microscopy (SEM). Finally, the suitability of the 


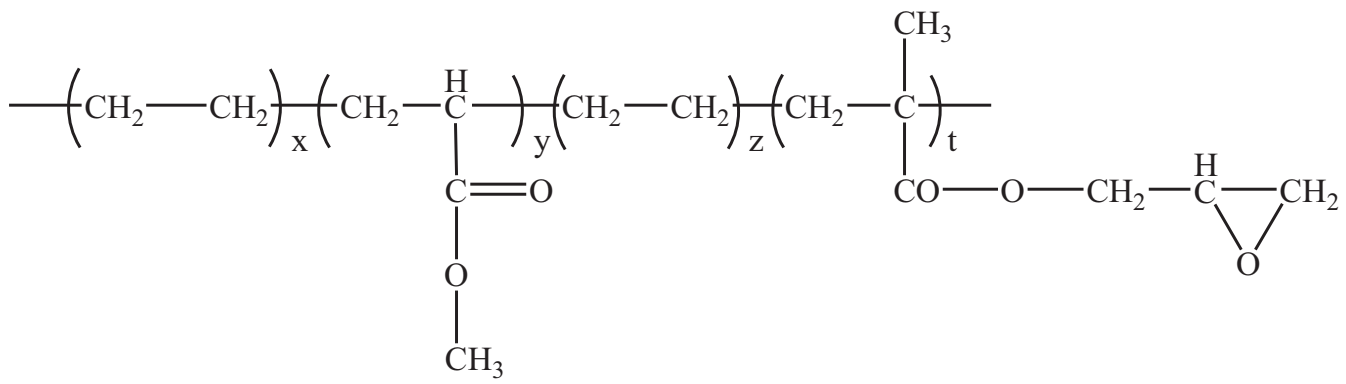

Figure 1. Chemical structure of EAG.

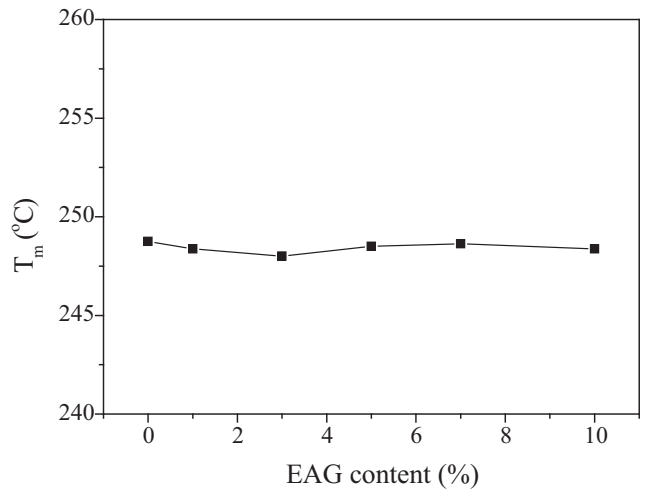

(a) PET

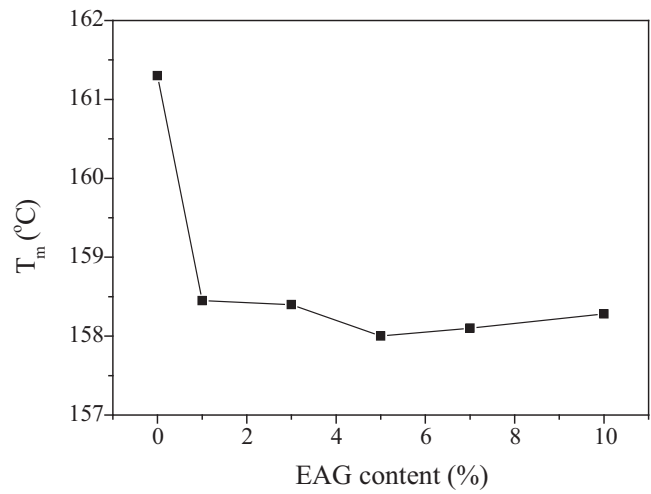

(b) PP

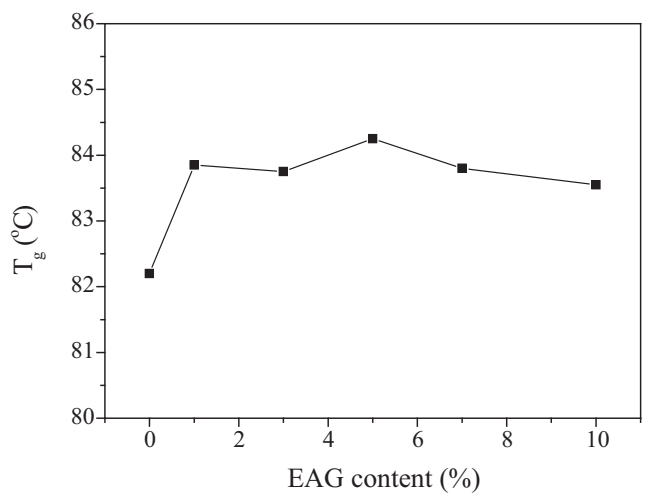

(c) PET

Figure 2. $T_{\mathrm{m}}$ and $T_{\mathrm{g}}$ of PET and PP in PET/PP blends as a function of EAG content.

synthesized fibres for making wigs was tested by evaluating the curl properties of the fibres.

\section{Experimental}

\subsection{Materials}

PET and PP chips were obtained from Huvis Co. Ltd. (Super Bright, $M_{\mathrm{w}}=20,000$ ) and LG Chemical Co. Ltd. (Seetec H7511, MI = 13), respectively. The compatibilizer
EAG, which contained $24 \mathrm{wt} \%$ methyl acrylate and $8 \mathrm{wt} \%$ glycidyl methacrylate, was supplied by Arkema Company (LOTADER ${ }^{\circledR}$ AX8900). The chemical structure of EAG is shown in figure 1.

\subsection{Preparation of PET/PP blends}

The PET/PP blends were prepared using a twin-screw extruder (Brabender TSE 20/40D, $D=20 \mathrm{~mm}, L / D=40$ ). 


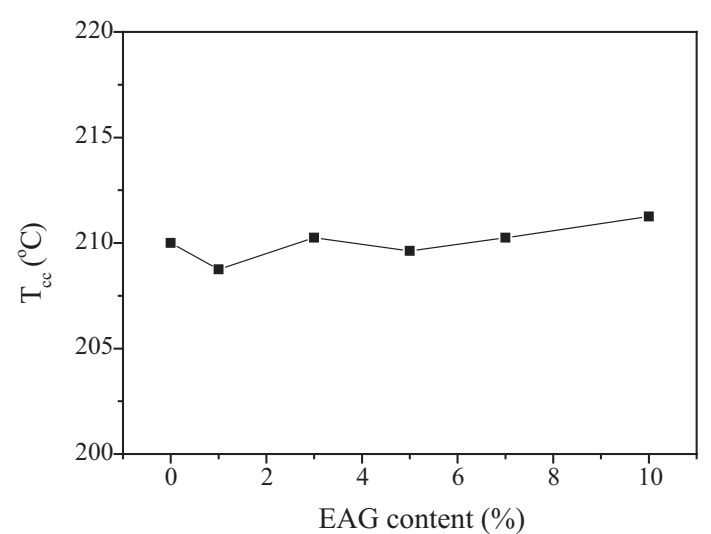

(a) PET

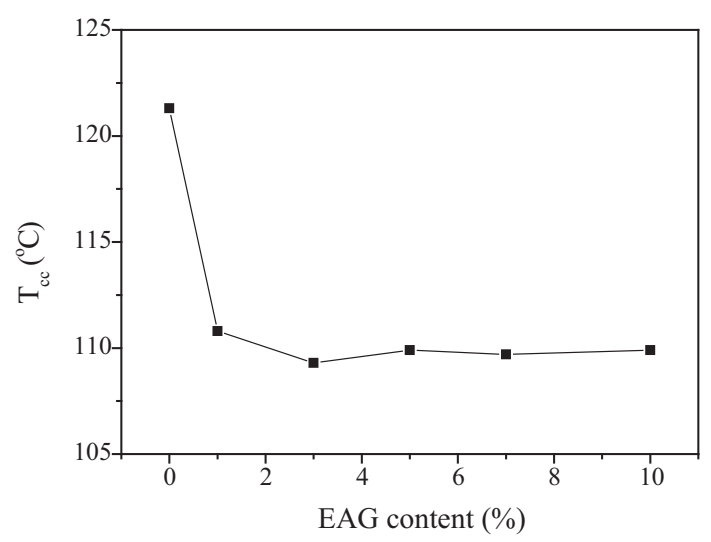

(b) PP

Figure 3. $T_{\mathrm{cc}}$ of PET and PP in PET/PP blends as a function of EAG content.

The extruder was divided into nine sections with temperature from 240 to $250^{\circ} \mathrm{C}$. The screw speed and feeding rate were $250 \mathrm{rpm}$ and $3 \mathrm{~kg} \mathrm{~h}^{-1}$, respectively. To improve the compatibility between PET and PP, two reverse segments were set in the screw of sections 3 and 9. The extrudate was cooled in air and cut into pellets using a rotary cutter.

\subsection{Preparation of PET/PP blend fibres}

To investigate the effect of the EAG content on the properties of the resulting fibres, blend chips were prepared using the twin-screw extruder for samples with a PET/PP ratio of 80/20 and EAG contents from 1 to $10 \%$. To investigate the effects of the PP content on the properties of the resulting fibres, blend chips were prepared for an EAG content of 5\% and PP contents from 5 to $20 \%$. Melt spinning was performed on the chips using a melt-spinning system at cylinder temperatures from 250 to $265^{\circ} \mathrm{C}$ and a die temperature of $260^{\circ} \mathrm{C}$. The flow rate and spinning speed were $400 \mathrm{~g} \mathrm{~min}^{-1}$ and $130 \mathrm{~m} \mathrm{~min}^{-1}$, respectively.

\subsection{Preparation of curl}

The PP content was varied from 5 to $20 \%$ and the EAG content was $5 \%$. A 15 -inch fibre $(2 \mathrm{~g})$ of the PET/PP blend being tested was spread on a piece of paper and then wound around an aluminium pipe with a diameter of $25 \mathrm{~mm}$. The pipe was heat-treated in a drying oven at $80^{\circ} \mathrm{C}$ for $60 \mathrm{~min}$ to set the curl and then cooled at room temperature. To check the loosening of the curl over time, the length of the curl was measured after periods from 1 to $72 \mathrm{~h}$.

\subsection{Characterization}

The thermal properties of the PET/PP blends were investigated using a DSC system (Q100, TA Instruments) for temperatures from 30 to $300^{\circ} \mathrm{C}$ at a heating rate of $10^{\circ} \mathrm{C} \mathrm{min}^{-1}$ and at a nitrogen flow rate of $50 \mathrm{ml} \mathrm{min}^{-1}$. The temperature dependence of the loss factor $(\tan \delta)$ of the PET/PP blends was analysed using a DMA system (RDS-II, Rheometries Co., Leather-head, UK) at a frequency of $1 \mathrm{~Hz}$, in the temperature range from -50 to $200^{\circ} \mathrm{C}$, and at a heating rate of $5^{\circ} \mathrm{C} \min ^{-1}$.

The morphologies of the fibres of the various blends were observed using an SEM system (S-3000N, Hitachi) at a magnification of $2000 \times$.

Density measurements were performed using a densitometer (AG204, MettleToledo), and the density was

Table 1. DMA data of PET/PP blends with various EAG contents.

\begin{tabular}{|c|c|c|c|c|c|c|c|c|}
\hline \multirow[b]{2}{*}{$\operatorname{PET}(\%)$} & \multirow[b]{2}{*}{$\mathrm{PP}(\%)$} & \multirow[b]{2}{*}{ EAG $(\%)$} & \multicolumn{2}{|l|}{ PET } & \multicolumn{2}{|l|}{$\mathrm{PP}$} & \multicolumn{2}{|l|}{ EAG } \\
\hline & & & Loss modulus (MPa) & $\tan \delta$ & Loss modulus (MPa) & $\tan \delta$ & Loss modulus (MPa) & $\tan \delta$ \\
\hline 80 & 20 & 0 & 93 & 106 & 11 & 20 & -59 & -51 \\
\hline 80 & 20 & 1 & 92 & 105 & 10 & 19 & -55 & -46 \\
\hline 80 & 20 & 3 & 93 & 108 & 12 & 14 & -53 & -43 \\
\hline 80 & 20 & 5 & 93 & 106 & 11 & 18 & -51 & -41 \\
\hline 80 & 20 & 7 & 90 & 105 & - & - & -49 & -41 \\
\hline 80 & 20 & 10 & 93 & 106 & - & - & -44 & -36 \\
\hline 100 & 0 & 0 & 94 & 104 & & & & \\
\hline 0 & 100 & 0 & & & 11 & 20 & & \\
\hline
\end{tabular}




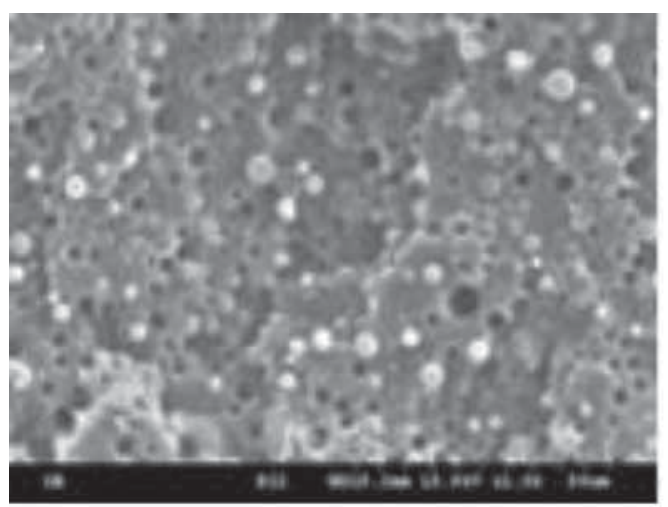

(a) $0 \% \mathrm{EAG}$

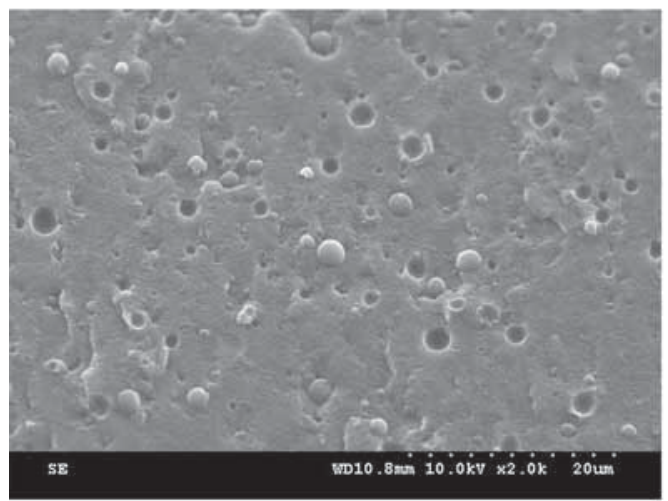

(c) $5 \% \mathrm{EAG}$

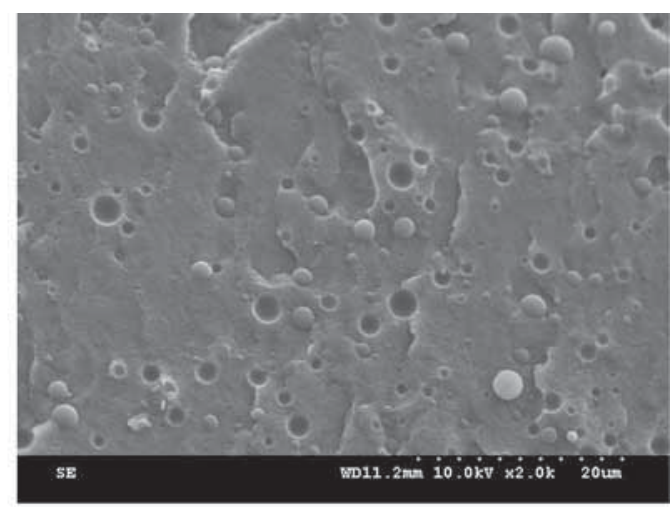

(b) $3 \%$ EAG

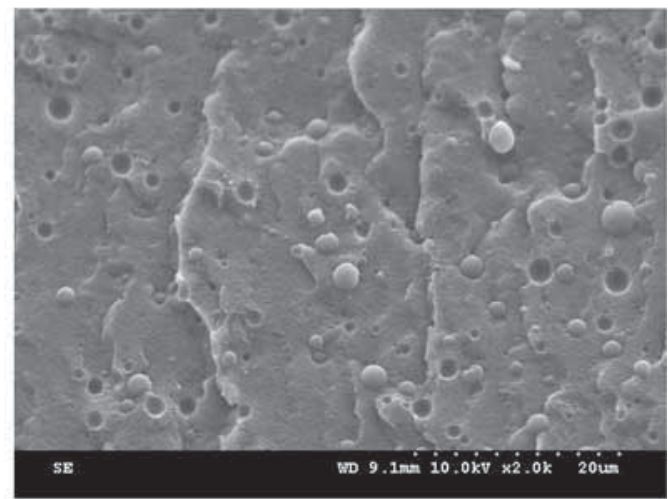

(d) $7 \% \mathrm{EAG}$

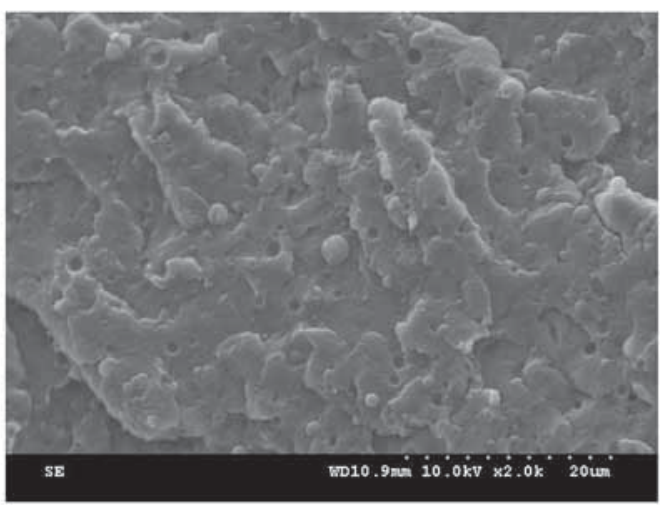

(e) $10 \% \mathrm{EAG}$

Figure 4. SEM photographs of cross-sections of PET/PP blends with different EAG contents (magnification of $2000 \times$ ).

calculated as follows:

$$
\rho=\frac{A}{A-B}\left(\rho_{0}-\rho_{\mathrm{L}}\right)+\rho_{\mathrm{L}}
$$

where $\rho$ is the density of the sample, $A$ the weight of the sample in air, $B$ the weight of the sample in ethanol, $\rho_{0}$ the density of ethanol and $\rho_{\mathrm{L}}$ the density of air $\left(0.0012 \mathrm{~g} \mathrm{~cm}^{-3}\right)$.

\section{Results and discussion}

\subsection{Thermal properties}

The melting temperature $\left(T_{\mathrm{m}}\right)$ and glass transition temperature $\left(T_{\mathrm{g}}\right)$ of PET and PP in the PET/PP blends were measured using DSC, and the results are shown in figure 2. When the EAG content was increased, the $T_{\mathrm{m}}$ values of PET in the blends were constant, whereas the $T_{\mathrm{g}}$ values of PET in 


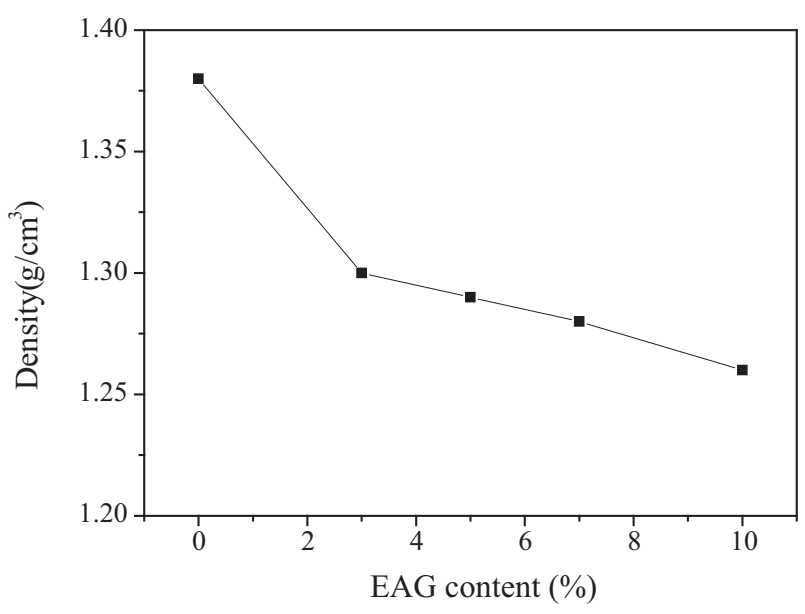

(a)

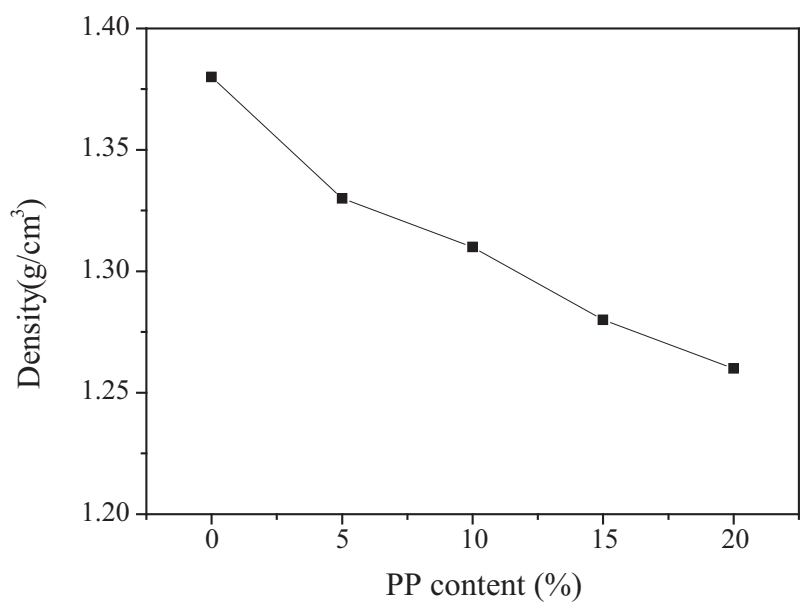

(b)

Figure 5. Density of PET/PP blend fibres as a function of (a) EAG or (b) PP content.

the blends increased slightly, as shown in figure $2 \mathrm{a}$ and $\mathrm{c}$. On the other hand, the $T_{\mathrm{m}}$ value of PP in the blends decreased significantly with the addition of $1 \%$ EAG as shown in figure $2 \mathrm{~b}$. This different behaviours of the two components is that EAG is more compatible with PP than with PET. The olefins in the EAG structure are compatible with PP, whereas the epoxy group at the end of EAG chain is ring-opened and combines with the end group of PET. Further, the number of olefins is higher than the number of epoxy groups. Thus, EAG is more compatible with PP than with PET. As the EAG content is increased, more EAG blended with PP, further hindering crystallization by this polymer and decreasing the $T_{\mathrm{m}}$ of PP in the PET/PP blends [5,19].

Figure 3 shows the cooling crystallization temperature $\left(T_{\mathrm{cc}}\right)$ values of the PET/PP blends as a function of the EAG content. When the EAG content was increased, the $T_{\mathrm{cc}}$ of PET did not vary significantly. However, the $T_{\mathrm{cc}}$ of PP decreased significantly with the addition of $1 \%$ EAG. This

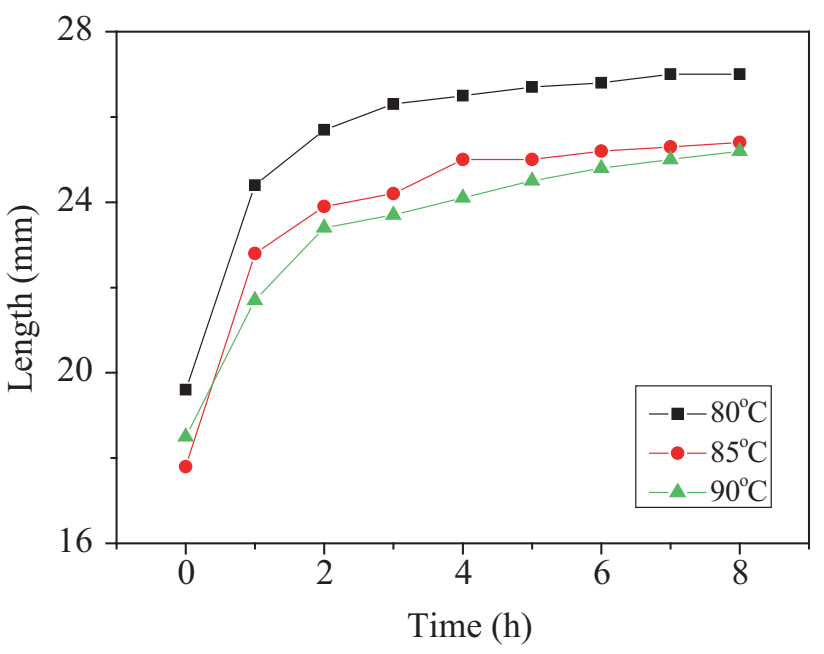

Figure 6. Change in curl length of $\mathrm{PP}$ with different curl-formation temperatures.

difference in outcome can also be attributed to EAG being more compatible with PP than with PET; thus, EAG permeates into PP and hinders crystal formation $[4,20]$.

Table 1 shows the DMA results for the PET/PP blends with the various EAG contents. When the EAG content was increased, the loss modulus and $\tan \delta$ values of PET in the PET/PP blends remained similar to those of neat PET. On the other hand, with an increase in the EAG content, the loss modulus and $\tan \delta$ values of PP in the blends decreased gradually, while those of EAG in the blends increased gradually. This result can be explained as follows: EAG contains $24 \%$ acrylic ester and $8 \%$ glycidyl methacrylate and has a greater number of reactive groups that can combine with PP. EAG had a more pronounced effect on the crystallization of PP and prevented PP from crystallizing, leading to decrease in the modulus of PP. In particular, when the EAG contents were $>5 \%$, the modulus peak of PP disappeared in the blends $[8,9]$.

\subsection{Morphology}

Figure 4 shows SEM images of the cross-sections of the PET/PP blends with different EAG contents. As shown in figure $4 \mathrm{a}$, numerous PP particles could be observed in the PET matrix, indicating that PP and PET were immiscible in the absence of EAG. The PP phase in the blends had a few small particles, as can be seen in figure $4 \mathrm{~b}-\mathrm{e}$. When the EAG content was increased, the number of PP particles and the size of the PP phase decreased, and a PP interface covered with EAG formed within the PET matrix [21-23]. Based on these results, the compatibility between PET and PP improved after increasing the EAG content. 


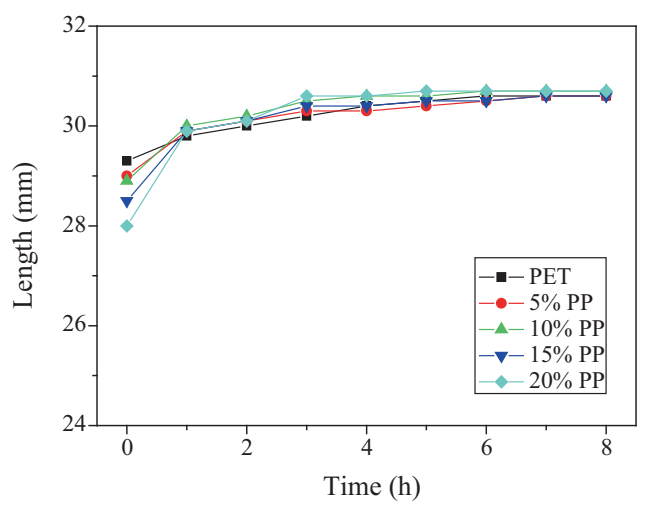

(a) $80^{\circ} \mathrm{C}$

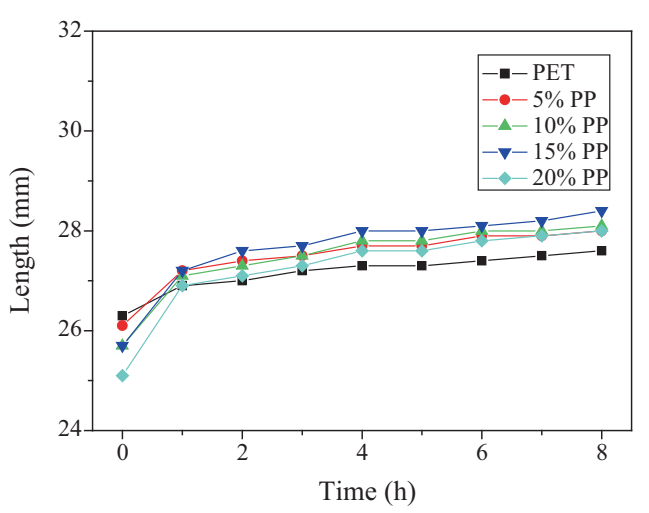

(b) $85^{\circ} \mathrm{C}$

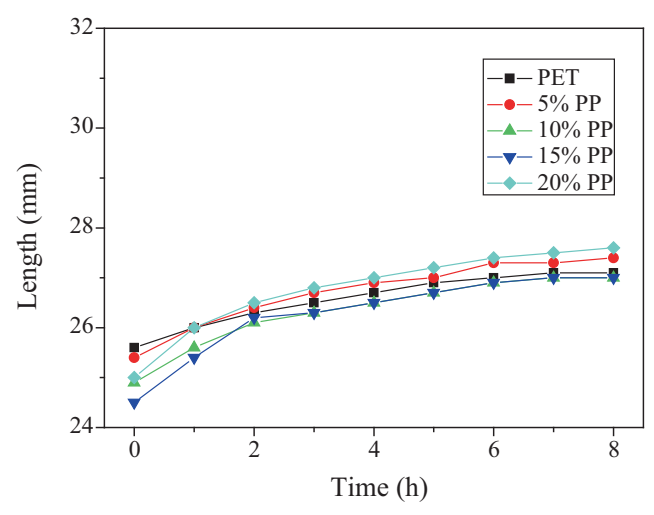

(c) $90^{\circ} \mathrm{C}$

Figure 7. Change in curl length of PET/PP blend fibres after treatment at various temperatures as functions of PP content.

\subsection{Physical properties}

Figure 5a shows the density of the fibres of a PET/PP blend with a PET/PP ratio of $80 / 20$ as a function of the EAG content. The density of the fibres decreased significantly as the EAG content was increased. Figure $5 \mathrm{~b}$ shows the density of the fibres of a PET/PP blend with 5\% EAG as a function of the PP content. The density of these fibres also decreased significantly with an increase in the PP content. One of the purposes of this study was to prepare a yarn with a density of $1.32 \mathrm{~g} \mathrm{~cm}^{-3}$, which is similar to that of a human hair. Fibres with this density could be achieved by adding 5-10\% PP and 5\% EAG to the PET matrix [24,25].

\subsection{Curl property}

Figure 6 shows the change in the curl length of PP after treatment at different curl-formation temperatures for $60 \mathrm{~min}$. As shown in the figure, the length of the initial curl decreased with an increase in the curl-formation temperature. The change in the curl length also decreased with an increase in the curl-formation temperature. Finally, the change in the curl length increased significantly as the treatment time was increased up to $2 \mathrm{~h}$ [26].

Figure 7 shows the change in the curl lengths of PET/PP blend fibres after treatment at various temperatures as a function of the PP content. The curl length of the fibres decreased with an increase in the treatment temperature suggesting that curls with desirable properties were formed at higher temperatures. The initial curl length decreased as the PP content was increased. This result indicated that the elastic force in the curls decreased significantly after the initial stage. Using this information on the effect of treatment temperature and PP content, fibres with larger curl lengths could be obtained [27].

Figure 8 shows photographs that document the extent of curl loosening for fibres that were made from PET/PP blends with different PP contents and different durations of treatment at $85^{\circ} \mathrm{C}$. After curl formation, the curl length of PP was smaller than that of PET, owing to the thermal shrinkage ratio of PP is higher than that of PET. This result was also attributable to 


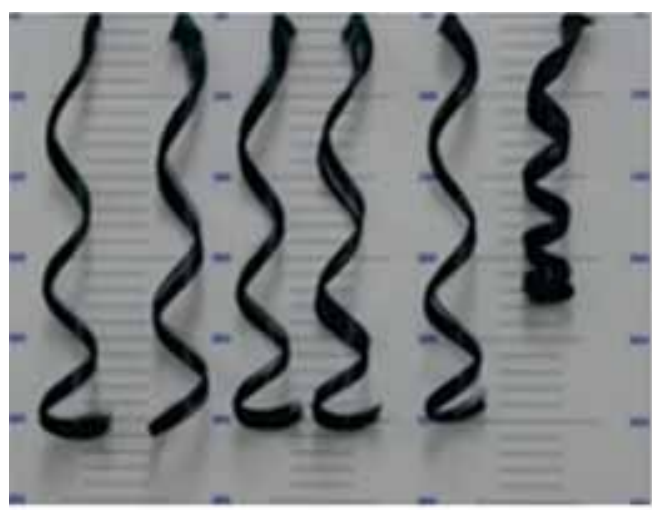

PP(\%) 0-5-10-15-20-100

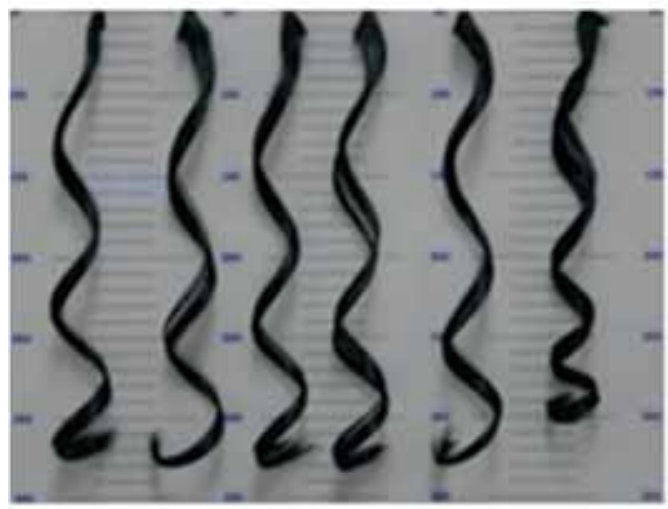

after $8 \mathrm{~h}$

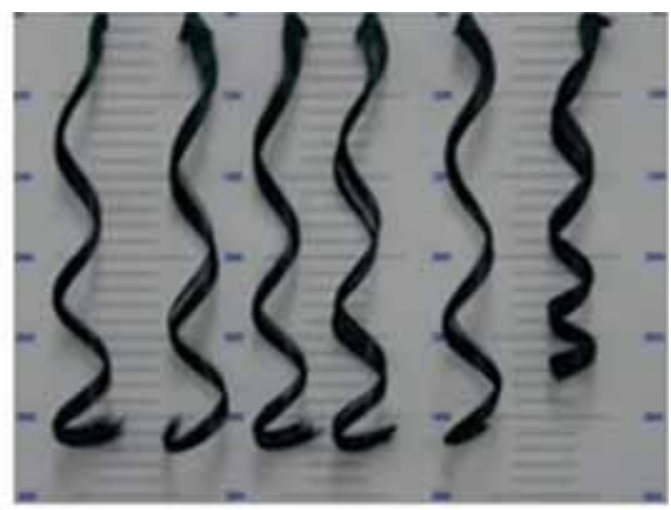

after $1 \mathrm{~h}$

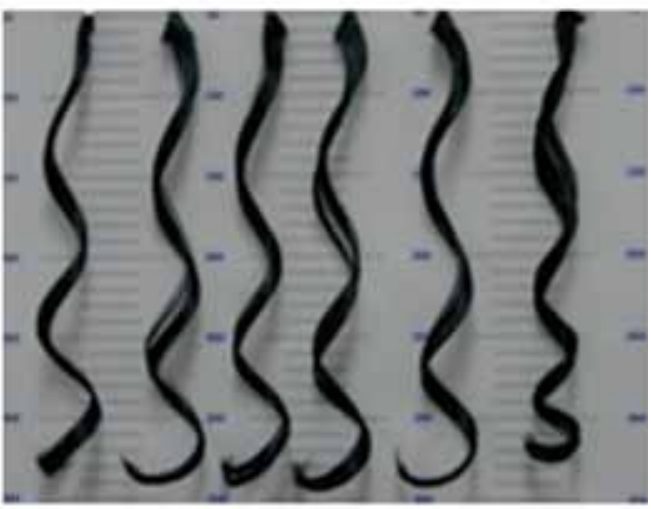

after $72 \mathrm{~h}$

Figure 8. Photographs of curl loosening of PET/PP blend fibres with different PP contents.

the sagging caused by the weight of the formed curls, given the low specific gravity of PP [28].

\section{Conclusions}

Different PET/PP blends and blend fibres were prepared using EAG as the compatibilizer, and the thermal properties, densities and morphologies of these blends were investigated. The $T_{\mathrm{m}}$ and $T_{\mathrm{cc}}$ values of PP in the PET/PP blends decreased significantly after the addition of $1 \%$ EAG. When the EAG content was increased, the loss modulus and $\tan \delta$ values of PET in the PET/PP blends remained similar to those of neat PET and the loss modulus and $\tan \delta$ values of PP in the blends decreased gradually. SEM results showed that both the number of PP particles in the PET matrix and the size of the PP phase decreased as the EAG content is increased. Further, the density of the PET/PP blend fibres decreased significantly with increase in both the EAG and PP contents. Finally, the curl length of the fibres decreased with an increase in the treatment temperature. The curl length of PP in the fibres was smaller than that of PET after curl formation.

\section{Acknowledgements}

This work was supported by the Industrial Strategic Technology Development Program (10050953) funded by the Ministry of Trade, Industry \& Energy (MI, Korea).

\section{References}

[1] Elabid A E A, Zhang J, Shi J, Guo Y, Ding K and Zhang J 2016 Appl. Surf. Sci. 37526

[2] Lepers J C, Favis B D and Tabar R J 1997 J. Polym. Sci. B: Polym. Phys. 352271

[3] Fu J H, Chen X D, Xu Q J, Wang R Y and Wang X J 2016 Polym. Compos. 371167

[4] Si X, Guo L, Wang Y and Lau K 2008 Compos. Sci. Technol. 682943

[5] Inuwa I M, Hassan A, Wang D Y, Samsudin S A, Haafiz M K M, Wong S L et al 2014 Polym. Degrad. Stab. 110137

[6] Bui T T L, Nguyen D A, Ho S V and Uong H T N 2016 J. Appl. Polym. Sci. 13343920

[7] Inuwa I M, Hassan A, Samsudin S A, Kassim M H M and Jawaid M 2014 Polym. Compos. 352029 
[8] Inuwa I M, Hassan A, Samsudin S A, Haafiz M K M and Jawaid M 2017 J. Vinyl Addit. Technol. 2345

[9] Papadopoulou C P and Kalfoglou N K 2000 Polymer 412543

[10] Calcagno C I W, Mariani C M, Teixeira S R and Mauler R S 2008 Compos. Sci. Technol. 682193

[11] Entezam M, Khonakdar H A, Yousefi A A, Jafari S H, Wagenknecht U, Heinrich G et al 2012 Macromol. Mater. Eng. 297312

[12] Akbari M, Zadhoush A and Haghighat M 2007 J. Appl. Polym. Sci. 1043986

[13] Kim H C, Kim D H, Park J, Lim J C and Park Y W 2009 Fiber. Polym. 10594

[14] Champagne M F, Huneault M A, Row C and Peyrel W 1999 Polym. Eng. Sci. 39976

[15] Yazdani-Pedram M, Vega H, Retuert J and Quijada R 2003 Polym. Eng. Sci. 43960

[16] Souza A M C and Caldeira C B 2015 J. Appl. Polym. Sci. 132 41892

[17] Heino M, Kirjava J, Hietaoja P and Seppälä J 1997 J. Appl. Polym. Sci. 65241
[18] Friedrich K, Evstatiev M, Fakirov S, Evstatiev O, Ishii M and Harrass M 2005 Compos. Sci. Technol. 65107

[19] Ershad-Langroudi A, Jafarzadeh-Dogouri F, Razavi-Nouri M and Oromiehie A 2008 J. Appl. Polym. Sci. 1101979

[20] Itim B and Philip M 2015 Polym. Degrad. Stab. 11784

[21] Yi X, Xu L, Wang Y L, Zhong G J, Ji X and Li Z M 2010 Eur. Polym. J. 46719

[22] Mostofi N, Nazockdast H and Mohammadigoushki H $2009 \mathrm{~J}$. Appl. Polym. Sci. 1143737

[23] Rizvi A, Park C B and Favis B D 2015 Polymer 6883

[24] Bang H J, Kim H Y, Jin F L and Park S J 2011 J. Ind. Eng. Chem. 17805

[25] Bang H J, Kim H Y, Jin F L and Park S J 2011 Bull. Korean Chem. Soc. 32541

[26] Park Y W, Song I J and Kim H C 2014 Fiber. Polym. 15 1078

[27] Chu K H, Park M, Kim H Y, Jin F L and Park S J 2014 Bull. Korean Chem. Soc. 351901

[28] Ho Y S, Kim H Y, Jin F L and Park S J 2012 Polym. Eng. Sci. 52149 